\title{
Incidence, Bacterial Profile and Antimicrobial Susceptibility Pattern of Ventilator Associated Pneumonia in Andhra Pradesh, India
}

\author{
Sreedevi Hanumantha ${ }^{1}$ and Deepti S. Patil ${ }^{2}$ \\ ${ }^{1}$ Department of Microbiology, Kodagu Institute of Medical Sciences, Madikeri-571201, \\ Karnataka, India \\ ${ }^{2}$ Department of Microbiology, SDM Medical College, Dharwad, Karnataka, India \\ *Corresponding author
}

\section{A B S T R A C T}

\begin{tabular}{|c|}
\hline Keywords \\
\hline $\begin{array}{l}\text { Bacterial profile, } \\
\text { Antimicrobial } \\
\text { susceptibility } \\
\text { pattern, Ventilator } \\
\text { associated } \\
\text { pneumonia }\end{array}$ \\
\hline Article Info \\
\hline $\begin{array}{l}\text { Accepted: } \\
15 \text { September } 2019 \\
\text { Available Online: } \\
10 \text { October } 2019\end{array}$ \\
\hline
\end{tabular}

\section{Introduction}

Hospital acquired infections (HAIs) or nosocomial infections, are important cause of morbidity and mortality among intensive care unit (ICU) patients in healthcare settings (Vincent et al., 1995). CDC has reported that the healthcare associated pneumonia (HAP) is the second most common HAI only after urinary tract infection accounting for about
Healthcare associated pneumonia (HAP) that includes ventilator-associated pneumonia (VAP) is the second most common Hospital acquired infection (HAI) only after urinary tract infection accounting for about $15-20 \%$ of HAIs. 39\% of HAP is VAP. Mortality rate among patients with VAP ranges from $24-50 \%$. Therefore, this study was undertaken with an aim to determine incidence, bacterial profile and antimicrobial susceptibility pattern of VAP in a tertiary care hospital at Andhra Pradesh, India. The patients were suspected of VAP, when Clinical Pulmonary Infection Score (CPIS) was six or greater. Endotracheal aspirate (ETA) from such patients was sent to culture and sensitivity test. Out of 85 patients, 23 patients developed VAP, based on CIPS and culture and sensitivity test. Incidence rate of VAP was found to be 20 per 1000 ventilator days. 22 out of 23 were bacterial pathogens and one was Candida albicans. Predominant bacteria was Acinetobacter spp (52\%) followed by Pseudomonas aerugenosa (26\%) and members of family Enterobacteriaceae (17\%). Gentamicin was found as most effective antimicrobial agent to all gram negative bacteria obtained. Gram negative bacteria are common pathogens of VAP throughout the world. However, antimicrobial susceptibility testing is necessary for determination of antimicrobial therapy as it shows regional variation. 
distributions of pathogens and drug-resistance patterns due to difference in diagnostic criteria of VAP (Campbell et al., 1996). Clinical pulmonary infection score (CPIS) is a better criteria and it takes into consideration certain parameters for evidence based diagnosis of VAP. These parameters are temperature, leukocyte count, ratio of partial pressure of arterial oxygen and percentage of inspired oxygen $\left(\mathrm{PaO}_{2} / \mathrm{FiO}_{2}\right)$, new infiltrates/ cavitation/ consolidation in chest radiograph, culture positivity, purulent secretions/ abundant secretion. A score of zero to two is given to each parameter. Sum total of scores, six or more is considered as significant (Schurink et al., 2004; Pratyusha et al., 2017).

Owing to morbidity and mortality attributed to VAP among seriously ill patients in ICUs, accurate and early diagnosis, timely intervention with appropriate antimicrobial agent apart from tackling underlying condition is crucial for optimal management of VAP. Therefore, this study was undertaken with an aim to determine incidence, bacterial profile and antimicrobial susceptibility pattern of VAP in a tertiary care hospital.

\section{Materials and Methods}

A prospective study approved by hospital ethical committee was carried out in a tertiary care hospital at Visakhapatnam, Andhra Pradesh, India for a period of six months (January 2016 to June 2016). 85 patients admitted in ICUs with intubation with EndoTracheal Tube (ETT) and on Mechanical Ventilation (MV), for a period of more than 48 hours were included in the study. Bundle of care was implemented to prevent VAP according to CDC NHSN guidelines. The patients were evaluated for clinical, radiological and laboratory parameters of VAP as and when indicated with reference to CPIS. If CPIS score was greater than six, EndoTracheal Aspirate (ETA) was sent to microbiology laboratory for culture and sensitivity testing with prompt documentation.

\section{Sample collection}

The patient was preoxygenated with $100 \%$ $\mathrm{FiO}_{2}$, using bagmask ventilation, if necessary with adequate sedation. A sterile suction catheter with suction trap was applied, instilling 3 to 5 milliliter of saline if an adequate specimen was not obtained. The suction tube was blindly introduced through the ETT wedged into the tracheobronchial tree and ETA was obtained cautiously (Medford et al., 2009). Immediately, the labeled specimens were sent to Microbiology laboratory for processing.

\section{Processing of specimens}

The specimens were inoculated on Blood agar and MacConkey agar with a sterile calibrated loop. The media was incubated at $37^{\circ} \mathrm{C}$ for 24 to 48hours under aerobic condition. Colony count of equal to more than or $10^{5}$ colony forming units per milliliter $(\mathrm{CFU} / \mathrm{ml})$ was considered as significant (Liang $\mathrm{Wu}$ et al., 2002). Identification of bacterial agents was done based on standard laboratory procedures (Forbes et al., 2007).

Antimicrobial susceptibility test was done according to Kirby Bauer method using antibiotic discs as per CLSI guidelines. The panel of antimicrobial agents was selected based on CLSI, M100 and local utilization.

\section{Results and Discussion}

A total of 85 patients were intubated with ETT and were on MV during the study period. Ventilator days were between 2 to 30 days for individual patients. A sum total of 1145 ventilator days were obtained during the study period. 23 out of 85 patients developed VAP based on CPIS, accounting to $27 \%$ of VAP cases and incidence rate obtained was 20 per 1000 ventilator days. 
Spectrum of causative agents of VAP is depicted in Table 1. All specimens yielded monomicrobial pathogen with significant colony count. Among 23 isolates obtained, 22 (96\%) were bacterial pathogens and one (four percent) was fungal agent. All the bacterial pathogens obtained were gram negative bacteria. These included 12 isolates of Acinetobacter spp (52\%), six isolates of Pseudomonas aeruginosa (26\%) and four members of family Enterobacteriaciae (17\%), namely Klebsiella pneumoniae, Escherichia coli and Enterobacter spp. Single fungal isolate obtained was Candida albicans (4\%). Three out of four members of family Enterobacteriaceae were of extended spectrum beta lactamase (ESBL) producers. ESBL was detected by combination disc method using both ceftazidime and amoxicillin-clavulanic acid (Thomas et al., 1992).

Antimicrobial susceptibility pattern of bacterial agents

Antimicrobial susceptibility pattern of bacterial agents of VAP is depicted in Table 2. Few antimicrobial agents that are not tested are indicated by NT in the table.

All the isolates of Acinetobacter spp, demonstrated $100 \%$ sensitivity to ampicillinsulbactam and gentamicin. $75 \%$ of Acinetobacter spp. was sensitive to amikacin and imipepem, $66.7 \%$ for levofloxacin, 33\% for cefepime. All were resistant to meropenem, cefotaxime, ceftriaxone and trimethoprim-sulfamethoxazole.

All the isolates of $P$. aeruginosa were susceptible to ciprofloxacin, carbepenems, gentamicin, amikacin and cefepime. $83.3 \%$ of isolates were sensitive to ceftazidime, levofloxacin, aztreonam and piperacillintazobactam.

All four isolates belonging to family Enterobacteriaceae were susceptible to ampicillin-sulbactam, amoxicillinclavulanate, levofloxacin, doripenem, imipenem, gentamicin, amikacin, tetracycline and chloramphenicol. The isolates were most resistant to ampicillin, cephalosporin group of drugs followed by meropenem and trimethoprim-sulfamethoxazole.

VAP is defined as pneumonia that occurs after 48 hours after ET intubation and initiation of MV. Incidence of VAP ranges from 6 to 52 cases per 100 patients (Apostolopoulou et al., 2003). In our study it was found to be $27 \%$ of VAP cases.

Table.1 Spectrum of causative agents of VAP

\begin{tabular}{|c|l|c|}
\hline SI no. & \multicolumn{1}{|c|}{ Organism } & $\begin{array}{c}\text { No. of } \\
\text { isolates }\end{array}$ \\
\hline $\mathbf{1}$ & Acinetobacter spp. & 12 \\
\hline $\mathbf{2}$ & Pseudomonas aeruginosa & 6 \\
\hline $\mathbf{3}$ & Klebsiella pneumoniae & 2 \\
\hline $\mathbf{4}$ & Escherichia coli & 1 \\
\hline $\mathbf{5}$ & Enterbacter spp. & 1 \\
\hline $\mathbf{6}$ & Candida albicans & 1 \\
\hline & Total & 23 \\
\hline
\end{tabular}


Table.2 Antimicrobial susceptibility pattern of bacterial pathogens

\begin{tabular}{|r|l|c|c|c|}
\hline $\begin{array}{r}\text { SI. } \\
\text { No. }\end{array}$ & Antimicrobial Agent & $\begin{array}{c}\text { Acinetobacter spp } \\
(\mathbf{n = 1 2})\end{array}$ & $\begin{array}{c}\text { P. aeruginosa } \\
(\mathbf{n = 6})\end{array}$ & $\begin{array}{c}\text { Enterobacteriacea } \\
\mathbf{e}(\mathbf{n = 4})\end{array}$ \\
\hline $\mathbf{1}$ & Ampicillin & $\mathrm{NT}$ & $\mathrm{NT}$ & $1(25 \%)$ \\
\hline $\mathbf{2}$ & Ampicillin-sulbactam & $12(100 \%)$ & $\mathrm{NT}$ & $4(100 \%)$ \\
\hline $\mathbf{3}$ & Amoxicillin-clavulanate & $\mathrm{NT}$ & $\mathrm{NT}$ & $4(100 \%)$ \\
\hline $\mathbf{4}$ & Ceftazidime & $2(16.7 \%)$ & $5(83.3 \%)$ & $1(25 \%)$ \\
\hline $\mathbf{5}$ & Ciprofloxacin & $2(16.7 \%)$ & $6(100 \%)$ & $3(75 \%)$ \\
\hline $\mathbf{6}$ & Levofloxacin & $8(66.7 \%)$ & $5(83.3 \%)$ & $4(100 \%)$ \\
\hline $\mathbf{7}$ & Doripenem & $2(16.7 \%)$ & $6(100 \%)$ & $4(100 \%)$ \\
\hline $\mathbf{8}$ & Imipenem & $9(75 \%)$ & $6(100 \%)$ & $4(100 \%)$ \\
\hline $\mathbf{9}$ & Meropenem & 0 & $6(100 \%)$ & $2(50 \%)$ \\
\hline $\mathbf{1 0}$ & Gentamicin & $12(100 \%)$ & $6(100 \%)$ & $4(100 \%)$ \\
\hline $\mathbf{1 1}$ & Amikacin & $9(75 \%)$ & $6(100 \%)$ & $4(100 \%)$ \\
\hline $\mathbf{1 2}$ & Aztreonam & $\mathrm{NT}$ & $5(83.3 \%)$ & $\mathrm{NT}$ \\
\hline $\mathbf{1 3}$ & Piperacillin-tazobactam & $2(16.7 \%)$ & $5(83.3 \%)$ & $3(75 \%)$ \\
\hline $\mathbf{1 4}$ & Cefepime & $4(33.3 \%)$ & $6(100 \%)$ & $1(25 \%)$ \\
\hline $\mathbf{1 5}$ & Cefotaxime & 0 & $\mathrm{NT}$ & $1(25 \%)$ \\
\hline $\mathbf{1 6}$ & Ceftriaxone & 0 & $\mathrm{NT}$ & $1(25 \%)$ \\
\hline $\mathbf{1 7}$ & Tetracycline & $\mathrm{NT}$ & $\mathrm{NT}$ & $4(100 \%)$ \\
\hline $\mathbf{1 8}$ & Trimethoprim- & 0 & $\mathrm{NT}$ & $2(50 \%)$ \\
\hline & sulfamethoxazole & & & \\
\hline $\mathbf{1 9}$ & Chloramphenicol & $\mathrm{NT}$ & $\mathrm{NT}$ & $4(100 \%)$ \\
\hline
\end{tabular}

Major risk factors associated with the development of VAP includes aspiration, oropharyngeal and gastric colonization, crossinfection and complications from the use of antibiotics and nasogastric and ETs (Craven and Steger, 1996). The causative agents of VAP may be part of the host's endogenous flora or they may be acquired from health care workers or other patients, devices, or the hospital environment (Craven, 2000). Earlyonset VAP is often caused by Staphylococcus aureus, Streptococcus pneumoniae, Haemophilus influenzae, while late-onset VAP is more frequently caused by multidrug resistant $P$. aeruginosa, Acinetobacter or Enterobacter spp., or MRSA (Joseph et al., 2010).

Microorganisms responsible for VAP vary from place to place. Though, there was no defined yard stick for diagnosing VAP in the past, it can now be identified with certainty via CPIS scoring system. Therefore, timely diagnosis of VAP is helpful in curbing its dangerous consequences, such as, increased antibiotic resistance, high mortality rate, prolonged hospital stay and increased cost (Craven, 2000; Chastre and Fagon, 2002; Joseph et al., 2012). Hence, studies on changing trends of etiological agents of VAP are pressing.

In our study, the incidence rate of VAP was 20 per 1,000 ventilator days which is very close to 19.87 per 1000 ventilator days at Madhya Pradesh, India (Tomar et al., 2017). It was found to be 17.5 per 1,000 ventilator days at Kurnool, Andhra Pradesh, India (Pratyusha et al., 2017). One large study conducted in France reported VAP rates of 
9.7-26.1 per 1,000 ventilator days (Zahar et al., 2009). The VAP rate was found in a wide range of 10 to 41.7 per 1000 ventilator days in various developing countries other than India (Arabi et al., 2008). In developed countries, the rates are much lower. In the US, the incidence of VAP ranges from 2 to 16 episodes per 1,000 ventilator days (Rosenthal et al., 2012). In Scotland, it is 3.5 per 1,000 ventilator days as reported by Scottish intensive care society audit group, NHS Scotland in 2017. Emphasis on quality improvement and patient safety with initiatives such as the introduction of VAP prevention bundles, together with robust reporting and quality assurance is believed to bring down the VAP rates in any given hospital setting (Daniel et al., 2015; Pugh et al., 2016).

VAP was entirely monomicrobial etiology in this study. A study done at Madhya Pradesh, India showed $94 \%$ of VAP cases to be monomicrobial (Tomer et al., 2017). However, at France it was found that $54.8 \%$ were polymicrobial (Trouillet et al., 1998) and at Greece, Athens, $27 \%$ of VAP cases were of polymicrobial in nature (Apostolopoulou et al., 2003).

Among 23 isolates obtained, 22 (96\%) were bacterial pathogens and one (four percent) was fungal agent in our study. Candida was found as causative agent in other studies also (Mohanty et al., 2016; Joseph et al., 2010).

All the bacterial isolates obtained were Gram negative bacteria in this study. Gram negative bacteria are nosocomial pathogens which colonize on healthy looking skin of ICU people and they can also harbor on instruments, catheters, and environment (Kuti et al., 2009).

Predominant bacteria in our study was Acinetobacter (52\%) followed by $P$. aeruginosa (26\%). K. pneumoniae was $8.6 \%$, whereas E.coli and Enterobacter spp. 4\% each. Similar result was observed with Acinetobacter as most frequent candidate pathogen contributing to $58 \%$ of cases at Iran (Hashemain et al., 2012). 38.11\% of VAP cases at Kurnool, India were caused by Acinetobacter, followed by $P$. aeruginosa (26.74\%), K. pneumoniae (14.85\%) and also MRSA (Satputeet al., 2017). At Chennai, Tamil Nadu, India Acinetobacter contributed to $31 \%$ of VAP cases (Nanthini Devi et al., 2018). However, at Madhyapradesh, India $P$. aeruginosa $(50 \%)$ was the leading isolate followed by Acinetobacter baumanii (17.64\%) and E. coli (14.70\%) (Tomar et al., 2017). Another study at Visakhapatnam, also found that $81 \%$ of pathogens were gramnegative bacilli with predominance of Pseudomonas spp (28.4\%) followed by $E$. coli (24.3\%), Klebsiella (12.3\%) and Acinetobacter spp was only 9.5\%. $19 \%$ of isolates were found to be gram-positive cocci with Staphylococcus aureus as predominant isolate (Kapaganty and Pilli, 2018). The most common organism isolated was $P$. aeruginosa, followed by MRSA, $K$. pneumoniae and A. baumannii at Odissa, India (Mohanty et al., 2016). In Pondicherry, India Enterobacteriaceae (25\%) and Acinetobacter spp. (25\%) followed by Methicillin sensitive S. aureus (13\%) were the most common pathogens causing early-onset VAP and Pseudomonas spp. (39\%) and Acinetobacter spp. (32\%) were the most common pathogens causing late-onset VAP (Joseph et al., 2010). In Korea the most commonly identified bacteria was shown to be $S$. aureus (44\%), A. baumanii, $P$. aeruginosa, S. maltophilia, $K$. pneumoniae, and Serratia marcescens in that order (Young Chi et al., 2012).

In our study, three of four members of Enterobacteriaceae family were EBSL producers. It was $56 \%$ in another study at 
Visakhapatnam (Kapaganty and Pilli, 2018), 25\% at Nagpur (Satpute et al., 2017). ESBL was produced by $50 \%$ of E. coli and $67 \%$ of $K$. pneumonia at Pondicherry (Joseph et al., 2010). Apart from ESBL, other studies revealed pathogens with AmpC production and MRSA as well (Joseph et al., 2010, 2012; Satpute et al., 2017)

In present study, gentamicin was found as most effective antimicrobial agent with $100 \%$ sensitivity to all gram negative bacteria. Acinetobacter and Enterobacteriaceae group were $100 \%$ sensitive to Ampicillin-sulbactam. In contrast to our study, $P$. aeruginosa exhibited $47.05 \%$ resistance to gentamicin at Madhyapradesh (Tomar et al., 2017). At Iran, imipenem showed superior activity over other tested antimicrobial classes against Enterobacteriaceae similar to our study (Hashemian et al., 2012). Gentamicin, amikacin and imipenem appear to be most effective antimicrobial agents which can be considered for empirical therapy for VAP in this region.

In conclusion, gram negative bacteria namely, Acinetobacter, Pseudomonas, E. coli, Klebsiella and Enterobacter are common pathogens of VAP throughout India and worldwide. However, antimicrobial susceptibility testing is necessary for determination of antimicrobial therapy as it shows regional variation.

\section{References}

Apostolopoulou E, Bakakos P, Katostaras T, and Gregorakos T. 2003. Incidence and Risk Factors for Ventilator-Associated Pneumonia in 4 Multidisciplinary Intensive Care Units in Athens, Greece. 2003. Respiratory Care. 48(7).

Campbell, GD, Niederman MS, Broughton WA, Craven DE, Fein AM, Fink MP, et al., 1996. Hospital-acquired pneumonia in adults: diagnosis, assessment of severity, initial antimicrobial therapy, and preventive strategies. A consensus statement. Am. J. Respir. Crit. Care Med. 153: 1711-1725.

Chastre J, Fagon JY. 2002. Ventilatorassociated pneumonia. Am J Respir Crit Care Med. 165:867-903.

CLSI. Performance Standards/or Antimicrobial Susceptibility Testing. 29th ed. CLSI supplement MlOO. Wayne, PA: Clinical and Laboratory Standards Institute; 2019.

Craven DE. 2000. Epidemiology of ventilator-associated pneumonia. Chest. 117: $186 \mathrm{~S}-7 \mathrm{~S}$.

Craven DE, Steger KA. 1996. Nosocomial pneumonia in mechanically ventilated adult patients: epidemiology and prevention in 1996.Semin Respir Infect. 11(1): 32-53.

Daniel M, Booth M, Ellis K, Maher S and Longmate A. 2015. Details behind the dots: How different intensive care units used common and contrasting methods to prevent ventilator associated pneumonia. BMJ Qual Improve Rep. 4(1): pii: u207660.w3069.

Forbes BA, Sahm DF, Weissfeld AS. Bailey and Scott's Diagnostic Microbiology. 2007. 12th ed. Philadelphia; Mosby Elsevier.

Hashemian SMR, Tabarsi P, Mohammad MM, Shamaei M, Nadji SA, Chitsazan M, et al., 2012. A prospective study of antibiotic susceptibility in patients with ventilator associated pneumonia. Anaesth, Pain \& Intensive Care. 16(1): 31-37.

Hyma Pratyusha Y, Aarthi V.2017. Bacteriological study on mechanically ventilated patients and incidence of ventilator associated pneumonia. Indian J Microbiol Res. 4(3): 338-340.

Joseph NM, Sistla S, Dutta TK, Badhe AS, Rasitha R, and Parija SC. 2010. 
Ventilator-associated pneumonia in a tertiary care hospital in India: role of multi-drug resistant pathogens. J Infect Dev Ctries. 4(4): 218-225.

Joseph NM, Sistla S, Dutta TK, Badhe AS, Rasitha D, and Parija SC. 2012. Outcome of ventilator-associated pneumonia: Impact of antibiotic therapy and other factors. Australasian Medical Journal. 5(2): 135-140.

Kapaganty VC, Pilli R. 2018. Microbiological profile of ventilator-associated pneumonia in the intensive care unit of a tertiary hospital in Visakhapatnam, India. Indian Journal of Microbiology Research. 5(2): 252-257.

Kuti JL, Shore E, Palter M, and Nicolau DP. 2009. Tackling empirical antibiotic therapy for ventilator associated pneumonia in your ICU: guidance for implementing the guidelines. Semin Respir Crit Care Med. 30(1):102-15.

Liang Wu C, Yang DI, Wang NY, Kuo HT, Chen PS. 2002. Quantitative Culture of endotracheal aspirates in the diagnosis of Ventilator-Associated Pneumonia in patients with treatment failure. CHEST. 122(2).

Magill SS., Edwards, JR., Bamberg, W., Beldavs ZG, Dumyati G, Kainer MA., et al., 2014. Multistate Point-Prevalence Survey of Health Care Associated Infection. N Engl J Med. 370:11981208.

Medford ARL, Husain SA, Turki HM, Millar AB. 2009. Diagnosis of ventilatorassociated pneumonia. Journal of Critical Care. 24: 473.

Mohanty D, Nayak MK, Raut K, Routray SS, Mishra D. 2016. Ventilator associated pneumonia in a ICU of a tertiary care Hospital in India. Indian Journal of Clinical Anaesthesia. 3(2):139-143.

Nanthini Devi P and Gomathi S. 2018. Multi Drug Resistant Acinetobacter Ventilator Associated Pneumonia in a Tertiary
Care Hospital. Int.J.Curr.Microbiol. App. Sci. 7(4): 1448-1463.

Peter JV, Chacko B, Moran JL. 2007. Comparison of closed endotracheal suction versus open endotracheal suction in the development of ventilator associated pneumonia in intensive care patients: An evaluation using meta analytic techniques. Indian J Med Sci. 61:201-11.

Pugh R, Harrison W, Harris S, Roberts H, Scholey G and Szakmany T. 2016. Is HELICS the right way? Lack of chest radiography limits ventilator-associated pneumonia surveillance in Wales. Front Microbiol. 7: 1271.

Rosenthal VD, Bijie H, Maki DG, Mehta Y, Apisarnnthananarak A, Medeiros EA, et al., 2012. International Nosocomial Infection Control Consortium (INICC) report, data summary of 36 countries, for 2004-2009. Am J Infect Control. 40(5):396-407.

Satpute TD and Shrikhande SN. 2017. Study of ventilator-associated pneumonia in a tertiary care hospital. Int. J. Adv. Res. 6(2):1770-1774.

Schurink CAM, Nieuwenhoven CAV, Jacobs JA, Rozenberg-Arska M, Joore HCA, Buskens E et al., 2004. Clinical pulmonary infection score for ventilator-associated pneumonia: accuracy and inter-observer variability. Intensive Care Med 30(2):217-224.

Thomson KS and Sanders CC. 1992. Detection of extended spectrum betalactamases in members of the family Enterobacteriaceae: comparison of the double-disk and three-dimensional tests. Antimicrob Agents Chemother. 36: 1877-1882.

Tomar APS, Kushwah A, and Shah H. 2017. Antimicrobial susceptibility pattern of Gram negative bacterial isolates from cases of Ventilator Associated Pneumonia in a tertiary care institute. 
International Journal of Medical Microbiology and Tropical Diseases. 3(3):129-132.

Trouillet JL, Chastre J, Vuagnat A, JolyGuillou ML, Combaux D, Dombret MC et al., 1998. Ventilator-associated Pneumonia Caused by Potentially Drugresistant Bacteria. Am J Respir Crit Care Med. 157, 531-539.

Vincent JL., Bihari DJ, Suter PM, Bruining HA, White J, Nicolas-Chanoin $\mathrm{MH}$, Wolff, Spencer RC, Hemmer M. 1995. The prevalence of nosocomial infection in intensive care units in Europe: Results of the European prevalence of infection in intensive care (EPIC) study. JAMA.274(8):639-44.

Yaseen Arabi, Al-Shirawi N, Memish Z, and Anzueto A. 2008. Ventilator-associated pneumonia in adults in developing countries: a systematic review International Journal of Infectious Diseases. 12 (5): 505-512.

Young Chi S, Kim TO, Park CW, Yeong Yu J, Lee B, Lee HS et al., 2012. Bacterial Pathogens of Ventilator Associated Pneumonia in a Tertiary Referral Hospital. Tuberc Respir Dis. 73(1):3233.

Zahar JR, Nguile-Makao M, Francais A, Schwebel C, Garrouste-Orgeas M, Goldgran-Toledano D et al., 2009. Predicting the risk of documented ventilator- associated pneumonia for benchmarking: construction and validation of a score. Critical Care Medicine. 37: 2545- 51.

\section{How to cite this article:}

Sreedevi Hanumantha and Deepti S. Patil. 2019. Incidence, Bacterial Profile and Antimicrobial Susceptibility Pattern of Ventilator Associated Pneumonia in Andhra Pradesh, India. Int.J.Curr.Microbiol.App.Sci. 8(10): 2058-2065. doi: https://doi.org/10.20546/ijcmas.2019.810.239 